\title{
Predicting acorn-grass weight gain index using non-destructive Near Infrared Spectroscopy in order to classify lberian pig carcasses according to feeding regime
}

\author{
By E. De Pedro-Sanz ${ }^{a, *}$, A. Serrano ${ }^{b}$, E. Zamora-Rojas ${ }^{a}$, A. Garrido-Varo ${ }^{a}$, J.E. Guerrero-Ginel ${ }^{a}$, \\ D. Pérez-Marín ${ }^{\mathrm{a}}$, J.M. García-Casco ${ }^{\mathrm{C}}$ and N. Núñez-Sánchez
}

\author{
a Ingeniería de Sistemas de Producción Agroganaderos, Escuela Técnica Superior de Ingeniería \\ Agronómica y de Montes, Universidad de Córdoba, Campus de Excelencia Internacional \\ Agroalimentario, Campus Rabanales, Crt. N-IV, km 396, 14014, Córdoba (España) \\ ${ }^{5}$ NIRSoluciones S.L., Parque Científico Tecnológico de Córdoba Rabanales 21, \\ 14014 Córdoba (España) \\ ${ }^{\circ}$ Departamento de Mejora Genética. Centro Nacional de I+D del cerdo Ibérico. INIA. \\ Crt. EX101, km 4,7, 06300 Zafra (España) \\ *Corresponding autor: pa1pesae@uco.es
}

\section{RESUMEN}

Predicción del Índice de Reposición en Montanera para la clasificación de canales de cerdo lbérico según régimen alimenticio mediante el análisis no destructivo por Espectroscopía del Infrarrojo Cercano

La clasificación en distintas categorías comerciales según régimen alimenticio de canales de cerdo Ibérico fue evaluada mediante el análisis no destructivo de muestras de tejido adiposo subcutáneo por Espectroscopía del Infrarrojo Cercano (NIRS). Partiendo de una aproximación cuantitativa para predecir el Índice de Reposición en Montanera (IRM) se establecieron una serie de criterios para proceder a su clasificación comercial. Se analizaron un total de 719 animales pertenecientes a diversas partidas, que recogen una amplia variabilidad de muestras de distintos regímenes alimenticios, campañas y sistemas productivos, para el desarrollo y evaluación de los modelos NIRS cuantitativos. Los resultados de validación externa de los modelos indicaron que es posible discriminar con una gran exactitud entre partidas de distintos categorías (Bellota, Recebo y Cebo), en base al espectro medio representativo de cada partida. Además, el análisis individualizado de los animales mostró un amplio consenso entre la información recibida de campo y la clasificación en base a la predicción del parámetro IRM por NIRS, sobre todo para categorías con características extremas (Bellota y Cebo).

PALABRAS CLAVE: Cerdo Ibérico - Clasificación - Espectroscopía Infrarrojo Cercano - Índice de Reposición en Montanera - Intacto - Régimen alimenticio - Tejido adiposo.

\section{SUMMARY}

Predicting Acorn-Grass Weight Gain Index using non-destructive Near Infrared Spectroscopy in order to classify lberian pig carcasses according to feeding regime

The classification of Iberian pig carcasses into different commercial categories according to feeding regime was evaluated by means of a non-destructive analysis of the subcutaneous adipose tissue using Near Infrared Spectroscopy (NIRS). A quantitative approach was used to predict the Acorn-Grass Weight Gain Index (AGWGI), and a set of criteria was established for commercial classification purposes. A total of 719 animals belonging to various batches, reflecting a wide range of feeding regimes, production systems and years, were analyzed with a view to developing and evaluating quantitative NIRS models. Results for the external validation of these models indicate that NIRS made clear differentiation of batches as a function of three feeding regimes possible with high accuracy (Acorn, Recebo and Feed), on the basis of the mean representative spectra of each batch. Moreover, individual analysis of the animals showed a broad consensus between field inspection information and the classification based on the AGWGI NIRS prediction, especially for extreme categories (Acorn and Feed).

KEY-WORDS: Acorn-Grass Weight Gain Index - Adipose tissue - Classification - Feeding regime - Iberian pig - Intact - Near Infrared Spectroscopy.

\section{INTRODUCTION}

Iberian pork products enjoy considerable national and international prestige, and have earned a worldwide reputation for their exceptional quality, outstanding nutritional characteristics and sensorial properties. This is particularly true of products made from pigs reared extensively in the dehesa, an agro-sylvo-pastoral ecosystem typical of the southwestern Iberian Peninsula (BOE, 2010a), which additionally benefit from the image associated with a traditional, and sustainable production system. Since the late 80 s and early 90s, however, Iberian pig production has gradually moved away from the traditional dehesa system. The new indoor and outdoor intensive production systems, also considered quality added based products, are produced by using compound feeds rather than natural resources of the dehesa for final fattening, what differs from the ideal traditional production system. The current range of commercial categories is covered under Spanish 
legislation by the Iberian Pig Quality Standard (BOE, 2007), extended until 2013 (BOE, 2010b), which, amongst other provisions, classifies Iberian pigs into four commercial categories as a function of feeding regime and production system: Acorn (i.e. free-range pigs fed exclusively on grass and acorns), Recebo (i.e. pigs fed on acorns and grass supplemented with compound feeds in an outdoor system), Field Feed (i.e. pigs fed on compound feeds in an outdoor extensive system), and Feed (i.e. pigs fed on compound feeds in an indoor intensive system). This legislation is currently the object of considerable debate amongst stakeholders in the Iberian pig sector. The various proposals put forward by the pork industry and regional governments share certain common features, including the recognition of the need to improve traceability and monitor certified products, and of the need to simplify commercial categories by modifying certain technical aspects of the current legal requirements (ASICI, 2012).

Several analytical techniques have confirmed the existence of differences in muscle and fat tissue as a function of the feeding regime used in finishing lberian pigs; in many cases, these techniques have enabled carcasses to be assigned to different commercial categories. However, as noted by Garrido-Varo et al. (2004), a major drawback to the procedures involved both in the current field inspection system and in many of the new certification techniques is that they are costly and laborious.

The industry therefore needs rapid, reliable, lowcost methods for the quality control of Iberian pigs and pork products. Near infrared technology (NIRS) has several advantages over other techniques for the quality control and traceability of pig carcasses and of lberian pork products (Garrido and De Pedro, 2007): it provides rapid results, and requires little or no sample preparation; it is safe for the environment and for the operator (it does not use chemical reagents nor produce chemical waste), it is versatile (it enables simultaneous analysis of several constituents) and flexible, it can be applied to all kinds of products; additionally, the cost per sample in a routine analysis is substantially lower than that of conventional techniques. Moreover, recent advances in NIRS instrumentation have enabled the development of a wide variety of devices, ranging from high-resolution equipment for laboratory use to small, compact, portable instruments for use in the industry and field.

A number of papers have highlighted the reliability of NIRS technology in a range of applications. Research has demonstrated that the analysis of melted fat samples, of intact subcutaneous tissue, and even of live animals, coupled with the use of various mathematical algorithms, represents a promising approach both for predicting the proportions of the four major fatty acids (oleic, palmitic, stearic and linoleic) (De Pedro et al., 1992; García-Olmo et al., 2001; GonzálezMartín et al., 2002, 2003; Garrido-Varo et al., 2004;
Fernández-Cabanás et al., 2007; Pérez-Marín et al., 2007, 2009 and 2010) and for classifying samples by feeding regime simply on the basis of spectral information (Hervás et al., 1994; De Pedro et al., 1995; García-Olmo et al., 2009; Arce et al., 2009: Zamora-Rojas et al., 2012).

The present work studies an alternative and/or complementary approach to the above mentioned techniques, which means NIRS prediction of the fatty acid profile and classification based on spectral information, for the non-destructive NIRS analysis of subcutaneous adipose tissue samples to classify Iberian pig carcasses according to feeding regime. For this purpose, quantitative multivariate NIRS models were developed to predict live-weight gain due to natural resources of the dehesa (acorns and grazing) during the finishing period prior to slaughter (Acorn-Grass Weight Gain Index - AGWGI). Models were developed using a broad-based sample set covering a wide range of production systems: mast-feeding (Montanera) in different areas, over different intervals and in different years; mast-feeding combined with varying amounts of compound feeds; special formulation with higher contents in oleic acid and standard compound feeds alone in outdoor or indoor intensive systems.

\section{MATERIAL AND METHODS}

\subsection{Sample set}

A total of 702 pieces of subcutaneous adipose tissue taken from the officially-recommended anatomical site (BOE, 2004) on the carcasses of Iberian pigs slaughtered in different years and in various parts of Spain were used. Detailed information on the various batches from which samples were drawn for analysis can be found in tabular form in García-Casco et al. (2013). The identification codes employed are those used in that paper. Samples obtained in slaughterhouses were placed in appropriately-tagged plastic bags and transported to the laboratory at the University of Córdoba, where they were stored at $-20^{\circ} \mathrm{C}$ until 24 hours before NIRS analysis.

\subsection{Acorn-Grass Weight Gain Index for Iberian pigs}

The Acorn-Grass Weight Gain Index (AGWGI) was defined for the purposes of this study as the live-weight gain recorded during the final fattening period using the natural resources of the dehesa system (acorns and open grazing). The AGWGI was determined using only samples from animals definitely known to have been raised on commercial feed and/or acorns; thus, of the 702 samples received, the AGWGI sample set contained only 502 samples drawn from various batches. The AGWGI was calculated on the basis of the following equation: 


$$
A G W G I=\frac{F W-S W}{F}-\frac{W}{F}
$$

where FW is the final live weight $(\mathrm{kg})$; SW is the animal's weight at the start of the final fattening period $(\mathrm{kg}) ; \mathrm{W}$ is the estimated weight gain based on compound feed consumed $(\mathrm{kg})$ and $F$ is a conversion factor $(\mathrm{F}=11.5 \mathrm{~kg}$, the value traditionally corresponding to one arroba). An AGWGI value of 0 was assigned to batches raised exclusively on compound feed, regardless of possible access to grazing, under both "Feed" and "Field Feed" systems; the single exception was batch CA08-3, for which information was available on individual weight gain and compound feed consumption. This batch was initially intended for "Recebo" but failed to fulfil legal requirements and was finally downgraded to "Field Feed".

For the classification of pigs by feeding regime, only three categories were used (Acorn, Recebo and Feed), Field Feed and Feed being conflated into a single category. Since the AGWGI is a quantitative index, cut-off values were essential. In light of the previous experience of the AgroLivestock Production System Engineering Group at the University of Córdoba in batch monitoring over a wide range of pig fattening systems (De Pedro, 2001), as well as data provided by qualified field workers and current legislative criteria, a minimum value of 4 was established for the "Acorn" category, corresponding to a weight gain of $46 \mathrm{~kg}$ under a mast-feeding system (i.e. the minimum weight gain laid down for pigs finished in the dehesa by the Iberian Pig Quality Standard). A minimum cutoff value of 2 was used for the "Recebo" category, which thus covered AGWGI values from 2 to 4 . Finally, AGWGI values of less than 2 were classed as "Feed". The general procedure for classifying carcasses is outlined in Figure 1.

\subsection{Near Infrared Spectroscopy analysis}

A Foss NIRSystems 6500 spectrophotometer (Foss-NIRSystems Inc., Silver Spring, MD, USA) equipped with a fiber optic probe was used for the non-destructive analysis of subcutaneous adipose tissue samples under laboratory conditions at room temperature (wavelength range 400-2500 $\mathrm{nm}$ with a spectral interval step of $2 \mathrm{~nm}$ ). Skinfree transverse sections of subcutaneous adipose tissue were analyzed for each sample. Duplicate spectra were collected, turning the sample $180^{\circ}$ between measurements.

The WinISI ${ }^{\mathrm{TM}}$ software package version 1.50 (Infrasoft International, Port Matilda, PA, USA) was used for data collection and treatment. In order to eliminate spectral noise at the beginning and end of the complete spectral region, the regions between 400-450 $\mathrm{nm}$ and between 2208-2498 $\mathrm{nm}$ were discarded; the latter region is particularly associated with a poor signal/noise ratio, due to the interference taking place in fiber-optic light transmission (Zamora-Rojas et al., 2012).

\subsection{Multivariate data analysis}

Spectral repeatability. Spectral repeatability of intact skin-free subcutaneous fat was evaluated using the Root Mean Squared (RMS) statistic. This statistic was used to eliminate spectra displaying considerable variations and a poor signal/noise ratio. The RMS statistic is the averaged root mean square of differences between the different subsamples scanned at $n$ wavelengths (Shenk and Westerhaus, 1995, 1996). All samples displaying RMS values higher than the cut-off limit, set by Zamora-Rojas et al. (2012) at $5.012 \mu \mathrm{log}(1 / \mathrm{R})$ for the range 450-2208 $\mathrm{nm}$, were discarded from the final set before averaging the spectra for each sample.

Principal Component Analysis and detection of spectral outliers. The detection of spectral outliers was performed following the well-known procedure described by Shenk and Westerhaus (1996). Samples with Global Mahalanobis (GH) Distance (distance between each sample and the center of the spectral population) values greater than 3 were considered outliers. In order to determine the center of the spectral population and the position of each sample, a Principal Component Analysis (PCA) was performed decomposing and compressing the data matrix. For spectral pretreatment, a Standard Normal Variate (SNV) plus

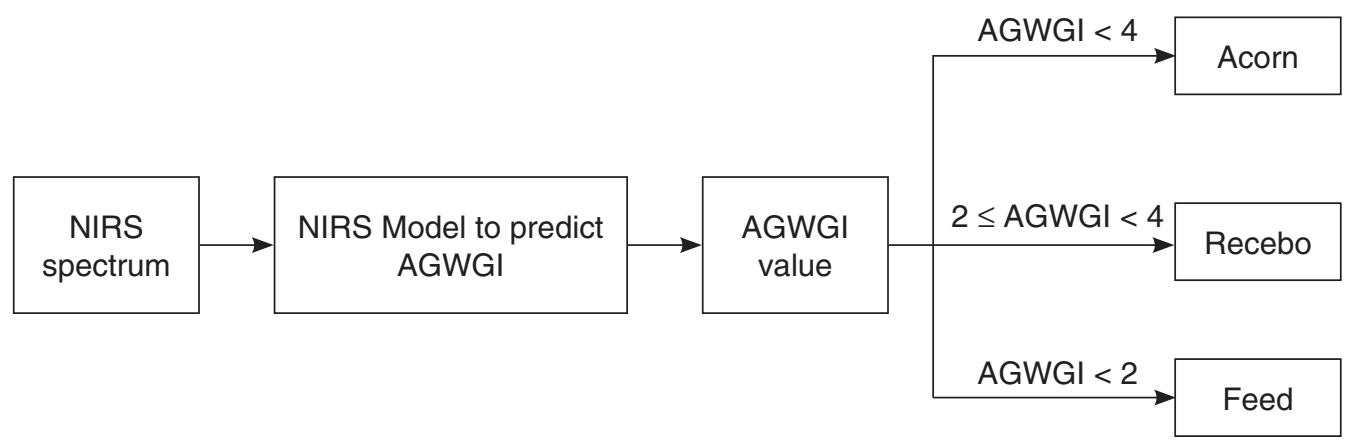

Figure 1

Schematic diagram showing the methodology followed to classify lberian pig samples in different feeding regime categories based on the prediction of the AGWGI parameter. 
Detrending (DT) (Barnes et al., 1989) procedure was used to remove the multiplicative interferences of scatter, and a derivative mathematical treatment $(1,4,4,1)$ was applied, where the first digit is the order of the derivative, the second is the gap over which the derivative is calculated, the third is the number of data points in a running average or smoothing, and the fourth is the second smoothing (ISI, 2000).

Definition of calibration and validation sets. Once spectral outliers had been removed, the number of samples for each feed category and production system was unbalanced; to minimize this, the "Feed" sample set was reduced by one fifth, using the SELECT algorithm (Shenk \& Westerhaus, 1991) included in the WinISI ${ }^{\mathrm{TM}}$ software to choose the most representative samples of this feeding regime. This algorithm, based on spectral distance calculations (Mahalanobis distance), was designed to remove samples with spectra similar to others.

Samples for calibration and validation sets were then selected following Shenk \& Westerhaus (1991), using the CENTER algorithm. All the samples of the final sample set were ordered based on the $\mathrm{GH}$ distance to the centre of the population based on a PCA, and one of every five samples in the set was selected to be part of the validation set. After ensuring that the internal validation set $(80$ samples) included samples of all feeding regimes included in the Quality Standard, and of all three study years (2008-2009, 2009-2010 and 20102011), the remaining 320 samples were assigned to the calibration set (Table 1).

Development and evaluation of quantitative NIRS models. Multivariate NIRS models for predicting acorn-grass weight gain index were developed using various mathematical spectral pretreatments: no scatter correction, SNV combined with DT or MSC (Multiplicative Scatter Correction) to correct scattering. In this case, six derivative mathematical treatments were tested, three for the first derivative $(1,4,4,1 ; 1,10,5,1 ; 1,10,10,1)$ and three for the second $(2,5,5,1 ; 2,10,5,1 ; 2,10,10,1)$, in order to correct baseline shifts and select the optimum combination to get the best NIRS predictions for AGWGI parameter. As above, each derivative has four numbers: the first digit indicates the order of the derivative, the second is the gap over which the derivative is calculated, the third is the number of data points in a running average or smoothing, and the fourth is the second smoothing (ISI, 2000). Chemical outliers were detected using the Student T test to check for differences between reference and predicted values; samples with a $T$ value of over 2.5 were considered outliers (Howard and Workman, 2003). For all regression models, a maximum of 3 cross-validation steps were used to detect outliers.

According to the authors experience in this topic, three different spectral regions were evaluated following the above mentioned spectra pretreatments: 450-2208 nm; 800-2208 nm and 1100-2208 nm, in order to identify the optimal wavelength range for this specific application. Regression models were obtained using the Modified-Partial Least Square Regression (M-PLSR) algorithm available in the WinISI ${ }^{\mathrm{TM}}$ 1.50 software package (Infrasoft International, Port Matilda, PA, USA). Cross-validation was used to select the optimal number of factors, with the purpose of avoiding over-fitting. For crossvalidation, the calibration set was partitioned into 4 groups; each group was then validated using a calibration obtained from the other samples. Finally, cross-validation errors of each partition were combined to obtain a Standard Error of Cross Validation (SECV). Other statistics used to select the best model were the Standard Error of Calibration (SEC) and the coefficient of determination for cross validation $\left(R_{\mathrm{cv}}^{2}\right)$. The Standard Error of Prediction (SEP) was also calculated (standard deviation of differences between NIR prediction and AGWGI reference values) using the 80 samples (internal validation set) not included in the model development to have a more reliable estimation of the model performance.

The main objective in developing models to predict the AGWGI was to assign carcasses to one of the three commercial categories: "Acorn", "Recebo" or "Feed". With this in mind, NIRS predictions of AGWGI values were subjected to qualitative evaluation based on the cut-off limits established in this study for each feeding regime in order to identify the regression models that

Table 1

Descriptive statistics of the Iberian sample sets used for calibration and internal validation

\begin{tabular}{|c|c|c|c|c|c|c|c|c|}
\hline \multirow{2}{*}{ No. samples } & \multicolumn{4}{|c|}{ Calibration set (320 samples) } & \multicolumn{4}{|c|}{ Validation set (80 samples) } \\
\hline & Acorn & Recebo & & Feed & Acorn & Recebo & & Feed \\
\hline $2008-2009$ & 39 & 32 & & 67 & 11 & 4 & & 12 \\
\hline $2009-2010$ & 24 & 21 & & 42 & 6 & 4 & & 16 \\
\hline $2010-2011$ & 29 & 5 & & 61 & 7 & 1 & & 19 \\
\hline Total & 92 & 58 & & 170 & 24 & 9 & & 47 \\
\hline Parameter & Min. & Max. & Mean & S.D. & Min. & Max. & Mean & S.D. \\
\hline AGWGI & 0 & 7.57 & 2.12 & 2.19 & 0 & 5.91 & 1.85 & 2.16 \\
\hline
\end{tabular}

Min.: minimum; Max.: maximum; S.D.: standard deviation. 
yielded the highest proportion of correctly-classified samples (\% CC).

External validation of NIRS models for predicting AGWGI. The best quantitative NIRS model for predicting AGWGI was externally validated using a set of 108 samples drawn from 6 batches of the year 2010-2011 (2 per feeding regime) monitored by qualified staff at Protected Denomination of Origin (PDO) centers (CA10-2, CE10-5, R10-3, R10-4, B10-5, B10-10) and not used in the development of this application, being a blind set for the authors. The evaluation of this blind set was based on predicting AGWIG values to assign a feeding regime category to each animal, since no individual data were available on live weight gain during mast-feeding, and compare that category to the field inspection information.

\section{RESULTS AND DISCUSSION}

The relevance of the fact that NIRS calibration has to start with robust and reliable spectral data is well known by NIRS practitioners. For this reason, once the repeatability was evaluated with the RMS statistics and samples with low repeatability removed from the initial file (502 samples with reference AGWGI values), the Global Mahalanobis distance to the center of the spectral population based on a PCA was calculated to detect samples too far from the center of the population. A total of 49 samples were eliminated since they had a $\mathrm{GH}$ value larger than 3 (Shenk and Westerhaus, 1991). The final set comprised 453 samples, for which an AGWGI value was available: 116 samples for the Acorn category, 67 Recebo samples, and 270 samples for the different types of feed used both in intensive and extensive systems (Feed). It is equally important to have a representative number of samples from each category in the structure of the calibration set to include the variability of the samples to be predicted (Garrido et al., 2004). In this sense, the spectral outlier free database was noticed to have a large number of "Feed" samples compared to the other groups; therefore, the number of samples from this feeding regime was reduced in one fifth, taking care to ensure a representative number of each type of feed and production system. The final set thus comprised 400 samples (116 Acorn, 67 Recebo and 217 Feed). This set was included in the calibration and validation set following the procedure explained in section 2.4. Table 1 shows the characteristics of both sets.

\subsection{Development and evaluation of NIRS regression models to predict AGWGI}

The best regression models developed and evaluated for each spectral region (450-2208 $\mathrm{nm}$; 800-2208 nm; 1100-2208 nm), considering the different scatter correction and derivative treatments, are shown in Table 2. The determination coefficient of cross validation $\left(R_{\mathrm{cv}}^{2}\right)$ for the best models in each wavelength ranges were: 0.79 (450$2208 \mathrm{~nm}), 0.74(800-2208 \mathrm{~nm})$ and 0.65 (1100-2208 $\mathrm{nm})$, respectively. This suggested the existence of relevant absorption bands between 450 and 1100 $\mathrm{nm}$ that provide useful information on the AGWGI prediction. This difference between spectral regions was also observed in the SEP values for the validation set which increased by $25 \%$ when the wavelength range was $1100-2208 \mathrm{~nm}$ compared to the other ones. The percentage of samples correctly classified (\% CC) in the three categories also revealed the relevance of including the wavelength range from 450 to $1100 \mathrm{~nm}$ in the models; whilst the $\%$ CC never rose above $80 \%$ using the 1100-2208 $\mathrm{nm}$ region. The best models obtained using the $800-$ $2208 \mathrm{~nm}$ reached $84.8 \%$ and $86.2 \%$ in the case of 450-2208 $\mathrm{nm}$ region. This confirms that the optimal spectral region for determining AGWGI using NIRS technology is $450-2208 \mathrm{~nm}$, which provides slightly better results than 800-2208 $\mathrm{nm}$. Henceforth, therefore, results for the other wavelength ranges were discarded.

The best model for the $450-2208 \mathrm{~nm}$ spectral region was obtained with a second derivative and MSC as scatter pre-treatment. There was a good fit

Table 2

Comparative of the different multivariate models developed for several wavelength ranges evaluated with different spectra pre-treatments

\begin{tabular}{|c|c|c|c|c|c|c|c|c|c|c|c|c|c|}
\hline $\begin{array}{c}\text { Wavelength } \\
\text { range and } \\
\text { interval step } \\
(\mathrm{nm}) \\
\end{array}$ & Min. & Max. & Mean & S.D. & $\begin{array}{c}\text { No. } \\
\text { samples }\end{array}$ & SEC & SECV & $\mathbf{R}_{\mathrm{cv}}^{2}$ & SEP & $C^{*}$ & & & $\begin{array}{l}\% \text { CC } \\
\text { Feed }\end{array}$ \\
\hline $450-2208 / 2^{a}$ & 0.0 & 6.6 & 2.09 & 2.15 & 308 & 0.83 & 0.97 & 0.79 & 0.91 & 86.2 & 75.0 & 77.8 & 93.6 \\
\hline $800-2208 / 2^{b}$ & 0.0 & 6.6 & 2.09 & 2.15 & 313 & 0.83 & 1.11 & 0.74 & 0.91 & 84.8 & 70.8 & 66.7 & 100.0 \\
\hline $1100-2208 / 2^{c}$ & 0.0 & 6.6 & .07 & 2.15 & 316 & 1.13 & 1.27 & 0.65 & 1.21 & 78.4 & 54.2 & 44.4 & 87.8 \\
\hline
\end{tabular}

These results indicate the best models (spectra pretreatment) for each wavelength range: a) MSC and $2^{\text {nd }}$ derivative $(2,10,5,1)$; b) No correction and $2^{\text {nd }}$ derivative $(2,5,5,1)$; c) MSC and $1^{\text {st }}$ derivative $(1,4,4,1)$.

Min.: minimum; Max.: maximum; S.D.: standard deviation; SEC: Standard Error of Calibration; SECV: Standard Error of Calibration of Cross Validation; $\mathrm{R}_{\mathrm{cv}}^{2}$ : determination coefficient of cross validation; SEP: Standard Error of Prediction; \%CC: Percentage of samples correctly classified.

"Percentage of sample correctly classified for the full validation set. 
between SEC, SECV and SEP, differing less than $20 \%$ between them, which indicates a suitable prediction model. The internal validation of this model for the prediction of AGWGI values using the 80 intact subcutaneous adipose tissue samples analyzed by NIRS (Table 1) showed an average $\%$ CC of $86.2 \%$, correctly classifying $75.0 \%$ of Acorn samples, $77.8 \%$ of Recebo samples and $93.6 \%$ of Feed animals (based on the interpretation of the AGWGI predicted value described in Figure 1 and comparing the categories with the field inspection information used as reference category) (Table 2). Pigs belonging to the Recebo category tend to be more difficult to classify, due to greater within-batch variation resulting from differences in feeding patterns; as a result, the \% CC for this category is generally lower (Zamora-Rojas et al., 2012). Here, however, the poorest rate of classification in the internal validation was obtained for the Acorn category. This is probably because the Acorn category included one batch (BE09-2) that was classified as Acorn although the animals comprising the batch had failed to achieve the $46 \mathrm{~kg}$ weight gain required by the Quality Standard. The NIRS model classified most animals in this batch as Recebo, since their AGWGI value remained below 4 ; this would account for the low rate of correct classification. Finally, despite the wide range of feeds used, the \% CC for the Feed category was the highest at around $94 \%$; samples classified by the NIRS model as Recebo mostly came from batch CA08-3, which was originally registered as Recebo and subsequently downgraded to "Field Feed", as indicated earlier. A number of animals in this batch may therefore have consumed a larger than average amount of acorns; their spectral profile would thus bear some similarity to that of Recebo batches.

\subsection{External validation of the best NIRS model for predicting AGWGI}

The best NIRS model was applied to a set of external samples $(N=108)$ drawn from various batches classified by the PDO, as indicated in the tables in García-Gasco et al. (2012): two Acorn batches (B10-5 and B10-4), two Recebo batches (R10-3 and R10-4) and two Feed batches, one intensive (CE10-5) and one extensive (CA102). Results for the prediction and subsequent classification of these example samples by commercial category are shown in Table 3. The overall correct classification rate was close to $90 \%$, i.e. higher than that obtained for the model internal validation. This improvement was largely due to the increase in \% CC for the Acorn category, from $75 \%$ to $96 \%$, confirming that the lower rates recorded for the internal validation were due to below-requirement weight gain in one batch rather than to model error. Percentages for the Recebo and Feed categories were similar to those obtained earlier, lower rates being recorded for Recebo due to intra-batch variations in feeding patterns. Additionally, since field classification is generally performed by batch rather than by individual animals, the model was applied to the mean representative spectrum for each batch (i.e. by calculating the mean value for all the animals in that batch). The predicted AGWGI value and NIRS classification for each batch is shown in Table 3 . All six batches were correctly classified according to the field classification provided by technical staff.

\subsection{Classification of study batches by NIRS-predicted AGWGI using the mean spectrum}

To ensure correct interpretation of the AGWGI value obtained by NIRS prediction, the mean representative spectrum for each study batch of animals (all batches described by García-Casco et al. 2013, although some of them did not have an AGWGI reference value) was evaluated using the best prediction NIRS model described in section 3.1.

The results for all 37 study batches are shown in Table 4, which also provides the field information supplied by technical staff. For the Acorn category, all batches were correctly classified except B09-

Table 3

Classification of the animals belonging to the external validation set: predicted AGWGI values versus field inspection category

\begin{tabular}{|c|c|c|c|c|c|c|c|c|}
\hline \multirow{2}{*}{ Batch } & \multirow{2}{*}{$\begin{array}{c}\text { No. } \\
\text { samples }\end{array}$} & \multirow{2}{*}{$\begin{array}{l}\text { Field } \\
\text { category }\end{array}$} & \multicolumn{3}{|c|}{ Classified as } & \multirow{2}{*}{$\begin{array}{c}\text { Samples } \\
\text { correctly } \\
\text { classified(\%) }\end{array}$} & \multirow{2}{*}{$\begin{array}{c}\text { AGWGI } \\
\text { prediction* }\end{array}$} & \multirow{2}{*}{$\begin{array}{c}\text { Classification } \\
\text { based on } \\
\text { AGWGI* }^{*}\end{array}$} \\
\hline & & & Acorn & Recebo & Feed & & & \\
\hline B10-5 & 14 & Acorn & 14 & 0 & 0 & 96.4 & 6.1 & Acorn \\
\hline B10-10 & 14 & Acorn & 13 & 1 & 0 & & 5.8 & Acorn \\
\hline R10-3 & 19 & Recebo & 0 & 12 & 7 & 71.1 & 2.2 & Recebo \\
\hline R10-4 & 19 & Recebo & 4 & 15 & 0 & & 3.5 & Recebo \\
\hline CA10-2 & 21 & Field-Feed & 0 & 0 & 21 & 100 & 0.5 & Feed \\
\hline CE10-5 & 21 & Feed & 0 & 0 & 21 & & -0.4 & Feed \\
\hline
\end{tabular}

${ }^{+}$Percentages calculated with the batches belonging to the same feeding regime category.

*Prediction based on the average spectrum for each batch. Then, the classification was based on the cut-off values defined in section 2.2 . 
Table 4

AGWGI results for the average spectra of each batch and their classification based on the feeding regime of the animals

\begin{tabular}{|c|c|c|c|c|}
\hline $\begin{array}{c}\text { Batch } \\
\text { identification }\end{array}$ & N. samples & $\begin{array}{l}\text { AGWGI } \\
\text { prediction }\end{array}$ & $\begin{array}{c}\text { Classification based } \\
\text { on AGWGI* }\end{array}$ & Field category \\
\hline B08-1 & 20 & 4.2 & Acorn & Acorn \\
\hline B08-2 & 32 & 5.2 & Acorn & Acorn \\
\hline B09-1 & 24 & 4.8 & Acorn & Acorn \\
\hline B09-2 & 29 & 3.9 & Recebo & Acorn \\
\hline B10-1 & 13 & 5.0 & Acorn & Acorn \\
\hline B10-2 & 16 & 4.6 & Acorn & Acorn \\
\hline B10-3 & 8 & 4.5 & Acorn & Acorn \\
\hline B10-4 & 8 & 4.9 & Acorn & Acorn \\
\hline B10-5 & 14 & 6.1 & Acorn & Acorn \\
\hline B10-6 & 15 & 4.3 & Acorn & Acorn \\
\hline B10-7 & 10 & 6.0 & Acorn & Acorn \\
\hline B10-8 & 12 & 5.5 & Acorn & Acorn \\
\hline B10-9 & 14 & 4.4 & Acorn & Acorn \\
\hline B10-10 & 14 & 5.8 & Acorn & Acorn \\
\hline R08-1 & 28 & 3.8 & Recebo & Recebo \\
\hline R08-2 & 12 & 3.2 & Recebo & Recebo \\
\hline R09-1 & 24 & 2.4 & Recebo & Recebo \\
\hline R09-2 & 25 & 3.0 & Recebo & Recebo \\
\hline R10-1 & 7 & 3.0 & Recebo & Recebo \\
\hline R10-3 & 19 & 2.2 & Recebo & Recebo \\
\hline R10-4 & 20 & 3.5 & Recebo & Recebo \\
\hline R10-5 & 11 & 3.8 & Recebo & Recebo \\
\hline CA08-1 & 12 & -0.2 & Feed & Field Feed \\
\hline CA08-2 & 23 & 0.8 & Feed & Field Feed \\
\hline CA08-3 & 39 & 1.4 & Feed & Field Feed \\
\hline CA09-1 & 24 & 0.8 & Feed & Field Feed \\
\hline CA09-2 & 25 & 0.4 & Feed & Field Feed \\
\hline CA09-3 & 25 & 1.3 & Feed & Field Feed \\
\hline CA10-1 & 24 & 0.4 & Feed & Field Feed \\
\hline CA10-2 & 21 & 0.5 & Feed & Field Feed \\
\hline CE08-1 & 32 & 0.0 & Feed & Feed \\
\hline CE09-1 & 24 & -0.5 & Feed & Feed \\
\hline CE10-1 & 5 & 1.3 & Feed & Feed \\
\hline CE10-2 & 8 & 1.3 & Feed & Feed \\
\hline CE10-3 & 14 & 0.1 & Feed & Feed \\
\hline CE10-4 & 24 & 0.8 & Feed & Feed \\
\hline CE10-5 & 22 & -0.4 & Feed & Feed \\
\hline
\end{tabular}

The batch identification labels refer to those described by García-Casco et al. (2013). AGWGI prediction was obtained with the best model reported in section 3.1. The feeding regime classification is based on the cut-off values established in section 2.2.

2, which was field-classified as Acorn although the animals comprising the batch had failed to achieve the $46 \mathrm{~kg}$ weight gain required by the
Quality Standard. In the Recebo category, despite the heterogeneous feeding patterns of the animals involved, all batches were correctly classified. Even 
so, some batches came close to the Acorn threshold (e.g. R08-1 and R10-5, with a predicted AGWGI of 3.8), while others approached the Feed cutoff (R091 and R10-3, with a predicted AGWGI between 2.4 and 2.2). Finally, all batches which had been fieldclassified as either Feed or Field Feed displayed predicted AGWGI values of less than 2. The lowest values were recorded for Duroc-cross pigs finished intensively on standard compound feed, and the highest for pigs reared extensively on higholeic formulated feeds, with grazing access. This suggests that the application of NIRS technology for the quantitative prediction of AGWGI enables the detection of pigs finished on Feed, trying to simulate the feeding based on acorn and grass in the dehesa by adding high-oleic formulated feeds and grazing supplementation. Finally, the "Feed" batch with the highest predicted AGWGI (1.4) was batch CA083 , comprising pigs that were initially finished as "Recebo" but failed to meet requirements for that category, and was eventually classed as Feed.

\section{CONCLUSIONS}

The model developed for predicting AGWGI by near-infrared spectroscopy enabled the fast, simple, non-destructive, objective and low-cost authentication of individual carcasses according to feeding regime. NIRS analysis of intact subcutaneous adipose tissue from Iberian pigs ensured accurate discrimination, in a few minutes, between pigs raised under different feeding regimes (Acorn and Feed), both using the mean spectrum of each batch as the individual spectrum for each animal. Acorn hams reach the highest prices in domestic and international markets.

Considering the database used in this study, the animals belonging to the Recebo group were classified with a lower reliable percentage in this feeding regime than the other. This is mainly explained, firstly, by the known uncertainty that exists in the carcass classification of this category, which is far from any analytical method. It is well-known that the accuracy and precision of the NIRS predicting models depend on accurate reference data. On the other hand, the choice of the animals for the compound feed or acorn, when they can choose between them, implies different characteristics in the fat deposition.

In view of the varied range of batches studied, representing animals from different years, production areas, production systems (dehesa, extensive, outdoor and indoor intensive) and feed/ grazing types, it is reasonable to conclude that this technique can be applied to pigs raised all over Spain, and could enable the authorities to establish an objective, sustainable and rapid system of certification. The application of NIRS technology, as a quality control system for Iberian pork products, serves not only to guarantee the quality of a highend product, thus meeting consumer demands, but also to ensure the conservation and sustainability of the traditional dehesa-based pig production system by establishing objective controls with a view to avoiding fraud and guaranteeing a fair price for a quality product. Moreover, this technology could additionally be used elsewhere in the sector as an integrated tool to support decision-making with regard to the monitoring of the raw material used for making lberian pork products.

\section{ACKNOWLEDGEMENTS}

This study was financed by INIA research project RTA 2008-00026-C07. The authors are grateful to the following staff at the Animal Production Department: Antonio López-López, Manuel Sánchez-Calderón and María del Carmen Fernández-Fernández. Analyses were performed using equipment at the NIRS/MIR Spectroscopy Unit, SCAI, University of Córdoba. Eduardo Zamora-Rojas is grateful to the Spanish Ministry of Education for financial support through a grant from the University Teacher Training programme (Formación del Profesorado Universitario).

\section{REFERENCES}

Arce L, Domínguez-Vidal A, Rodríguez-Estévez V, López-Vidal S, Ayora-Cañada MJ, Valcárcel M. 2009. Feasibility study on the use of infrared spectroscopy for the direct authentication of Iberian pig fattening diet. Anal. Chim. Acta 636, 183-189.

ASICI. 2012. EI MAGRAMA comunica a la interprofesional su propuesta para modificar la norma de calidad del ibérico. http://www.3tres3iberico. $\mathrm{com} / \mathrm{buscando/el-magrama-comunica-a-la-}$ interprofesional-su-propuesta-para-modific_823/. Accessed on 06/08/2012.

Barnes RJ, Dhanoa MS, Lister SJ. 1989. Standard normal variate transformation and detrending of near infrared diffuse reflectance spectra. Appl. Spectrosc. 43, 772-777.

BOE. 2004. no 283. ORDEN PRE/3844/2004, de 18 de noviembre, por la que se establecen los métodos oficiales de toma de muestras en canales de cerdos ibéricos y el método de análisis para la determinación de la composición de ácidos grasos de los lípidos totales del tejido adiposo subcutáneo de cerdos ibéricos.

BOE. 2007. no 193. Real Decreto 1469/2007, de 2 de noviembre, por el que se aprueba la norma de calidad para la carne, el jamón, la paleta y la caña de lomo Ibéricos. BOE № 264.

BOE. 2010a. Ley $7 / 2010$ para la Dehesa.

BOE. 2010b. no 188. Orden ARM/2139/2010, de 16 de julio, por la que se extiende el Acuerdo de la Asociación Interprofesional del Cerdo Ibérico, al conjunto del sector, y se fija la aportación económica obligatoria, para realizar actividades de promoción de los productos del cerdo ibérico, mejorar la información y conocimiento sobre las producciones y los mercados, y realizar programas de investigación, desarrollo, innovación tecnológica y estudios, para las campañas 2010-2011, 2011-2012 y 2012-2013.

De Pedro E. 2001. Calidad de las canales y de los productos del cerdo Ibérico: Técnicas de control 
y criterios de calidad, in Buxadé C, Daza A (Eds.), Porcino Ibérico: Aspectos claves. Mundi-Prensa, Madrid, p. 589-622.

De Pedro E, Garrido A, Bares I, Casillas M, Murray I. 1992. Application of near infrared spectroscopy for quality control of Iberian pork industry, in Hildrum KI, Isaksson R, Naes T, Tandberg A (Eds.) Near infrared spectroscopy bridging the gap between data analysis and NIR applications, Ellis Horwood, UK, p. 345-348.

De Pedro E, Garrido A, Lobo A, Dardenne P, Murray I. 1995. Objective classification of Iberian pig carcasses: GC versus NIR, in Batten GD, Flinn PC, Welsh LA, Blakeney AB (Eds.) Leaping ahead with near infrared spectroscopy, NIR Spectroscopy Group. Royal Australian Chemistry Institute, Melbourne, Australia, p. 291-295.

Fernández-Cabanás VM, Garrido-Varo A, García-Olmo J, De Pedro-Sanz E, Dardenne P. 2007. Optimisation of the spectral pre-treatments used for Iberian pig fat NIR calibrations. Chemometr. Intell. Lab. 87, 104112.

García-Casco J, Muñoz M, González E. 2013. Predictive ability of feeding system in Iberian pig by means of several analytical methods. Grasas Aceites. 64, 191. 200

García-Olmo J, Garrido-Varo A, De Pedro E. 2001. The transfer of fatty acid calibration equations using one set of unsealed liquid standardisation samples. J. Near Infrared Spec. 9, 49-62.

García-Olmo J, Garrido-Varo A, De Pedro E. 2009. Classification of real farm conditions Iberian pigs according to regime with multivariate models developed by using fatty acids composition or NIR spectral data. Grasas Aceites. 60, 233-237.

Garrido-Varo A, De Pedro E. 2007. The role of NearInfrared Spectroscopy in verifying label information in agro-forestry products, in Burns DA, Ciurczak EW (Eds.) Handbook of Near-Infrared Analysis ( $3^{\text {rd }}$ Edition). CRC Press. Taylor\& Francis Group, London UK.

Garrido-Varo A, García-Olmo J, Pérez-Marín MD. 2004. Analysis of Fats and Oils, in Roberts C, Workman J, Reeves J (Eds.) Near-Infrared Spectroscopy in Agriculture, Agronomy, Crop Science and Soil Science Societies of America, Madison, WI, USA., p. 487-558.

González-Martín I, González-Pérez C, HernándezMéndez J, Álvarez-García N, Lázaro SM. 2002. Determination of fatty acids in subcutaneous fat of Iberian breed swine by near infrared spectroscopy. A comparative study of the methods for obtaining total lipids: solvents and melting with microwaves. J.Near Infrared Spectrosc.10, 257-268.

González-Martín I, González-Pérez C, HernándezMéndez J, Álvarez-García N. 2003. Determination of fatty acids in the subcutaneous fat of Iberian breed swine by near infrared spectroscopy (NIRS) with a fiber-optic probe. Meat Sci. 65, 713-719.

Hervás C, Garrido A, Lucena B, García N, De Pedro E. 1994. Near infrared spectroscopy of Iberian pig carcasses using an artificial neural network. J.Near Infrared Spectrosc. 2, 177-184

Howard M, Workman Y. 2003. Statistics in Spectroscopy ( $2^{\text {nd }}$ edition). Academic Press, CA, USA.

ISI. 2000. The complete software solution using a single screen for routine analysis, robust calibrations and networking. Infrasoft International Sylver Spring MD, USA.

Pérez-Marín D, De Pedro-Sanz E, Guerrero-Ginel JE, Garrido-Varo A. 2009. A feasibility study on the use of near infrared spectroscopy for prediction of the fatty acid profile in live Iberian pigs and carcasses. Meat Sci. 83, 627-633.

Pérez-Marín D, Fearn T, Guerrero-Ginel JE, GarridoVaro A. 2010. Robustness in pig fat NIRS calibrations by orthogonal projection. Chemometr. Intell. Lab. 100, 36-40.

Pérez-Marín D, Garrido-Varo A, De Pedro E, GuerreroGinel JE. 2007. Chemometric utilities to achieve robustness in liquid NIRS calibrations: application to pig fat analysis. Chemometr. Intell. Lab. 87, 241-246.

Shenk JS, Westerhaus MO. 1991. Population structuring of near infrared spectra and modified partial least squares regression. Crop Sci. 31, 1548-1555.

Shenk JS, Westerhaus MO. 1995. Analysis of agriculture and food products by near infrared reflectance spectroscopy. Monograph, NIR Systems.

Shenk JS, Westerhaus MO. 1996. Calibration the ISI way., in Davies AMC, Williams PC (Eds.) Near infrared spectroscopy: The future waves, NIR Publications, Chichester. U.K, p. 198-202.

Zamora-Rojas E, Pérez-Marín D, De Pedro-Sanz E, Guerrero-Ginel JE, Garrido-Varo A. 2012. In-situ Iberian pig carcass classification using a microelectro-mechanical systems (MEMS)-based near infrared spectroscopy. Meat Sci. 90, 636-642.

Recibido: $16 / 10 / 12$ Aceptado: $26 / 1 / 13$ 